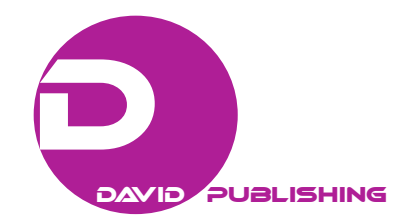

\title{
Forced Learning: Manifestations, Hazards, and Coping Strategies
}

\author{
CUI Shuang-yi \\ Nanjing Normal University, Nanjing, China
}

\begin{abstract}
"Forced learning” refers to the fact in China that some students are forced to learn by parents and teachers, regardless of their own wishes. Sometimes, some parents and teachers even force students to learn through disciplinary actions. Specifically, students are imposed in the following four aspects by parents and teachers: learning time, learning contents, learning frequency, and learning difficulty, so it caused bad consequences that some students' study took too much time, covered excess contents, is repeated too much and is too difficult. “Forcing learning” destroyed the nature of students, overdrew students' potential, and harmed students' physical and mental health. In order to change this existing situation of "forced learning", parents and teachers should clarify the nature of knowledge and broaden the way students acquire knowledge, activate students' inner study motive, and guide them to learn consciously and actively, create a harmonious educational environment, and make full use of students' “children” nature; parents and teachers strengthen cooperation to give students scientific guidance on psychology, emotion, and learning.
\end{abstract}

Keywords: forced learning, manifestations, hazards, strategies

\section{Introduction}

In order to improve academic record, some students are forced to learn by parents and teachers have become a common phenomenon in China's competitive educational situation. There is no doubt that students are immature individuals, so their learning needs certain external motivation and pressure to motivate them to learn. External motivation from parents and teachers can help students improve their learning efficiency. But when the external thrust exceeds the limit and becomes an extreme compulsion, students' inner study motive is greatly ignored and the meaning of students' learning is alienated. If student's study is only maintained by external compulsion, it will stifle students' interest, confine their thinking, erase their nature, and overdraw their potential. Based on it, this paper aims to help parents and teachers understand the hazards of "forced learning”, guide them to establish correct education ideas, and adopt the correct education methods to guide students to learn effectively.

\section{Manifestations of "Forced Learning”}

"Forced learning" refers to the fact in China that some students are forced to learn by parents and teachers, regardless of their own wishes. Sometimes, parents and teachers even force students to learn through disciplinary actions. In this case, students have no initiative and can only learn passively. "Forced learning" 
largely denies the consciousness and initiative of students' learning. "Forced learning" is not uncommon in the actual educational situation in China, and its main manifestations are as follows.

\section{Students Are Forced to Extend Their Study Time}

This is the most intuitive manifestation of "forced learning". It refers to parents or teachers in order to improve students' academic record, in addition to the necessary time of eating meals and sleeping, restrict the time for students to play and rest, eliminate all activities unrelated to learning, and want students to spend all their time in learning. While skilled knowledge and skills require sufficient time to practice, parents and teachers cannot encroach on the extracurricular time of the students without restriction. In China, the national document states that pupils cannot do homework for more than one hour, and middle school students can do homework for no more than 90 minutes. But according to a survey in China, $54.6 \%$ of primary school students spend about 1.6 hours a day doing homework, exceeding the prescribed time of $60 \%$. And $73.1 \%$ of junior high school students spend 2.2 hours a day doing homework, exceeding the prescribed time of $46.7 \%$ (Song \& Yang, 2014). It is obvious that in order to complete the homework imposed by the teacher, most students' sleep time is occupied, which leads to students' lack of sleep. In addition, some teachers deliberately extend the teaching time. For example, teachers often take up the time of self-study classes and activity classes forcibly. As a result, students bear the huge learning burden.

\section{Students Are Forced to Increase Learning Contents}

Some parents and teachers blindly add new learning contents or tutoring projects for students regardless of the students' own learning wishes and interest. For example, some parents force students to participate in a variety of specialty training classes on weekends or holidays. Under the banner of "developing students' interest and promoting students' development”, actually it takes up students' game and entertainment time, and even reduces the students' rest time. Some parents also force students to accept knowledge that is beyond students' current cognitive level. The main performance of this phenomenon is that some parents forced students to participate in various extra-curricular "new classes" during the winter and summer vacations to learn the subject knowledge of the next grade in advance. For example, students in the second grade are forced to learn the knowledge of the third grade or the fourth grade in advance. Confucius said that, "More haste, less speed”. Students are forced to learn symbolic knowledge too early not only violates the students' willingness to learn, but also does not respect the laws of students’ physical and mental development.

\section{Students Are Forced to Repeat the Same Learning Contents}

For example, some teachers force students to review and practice similar exercises over and over again. The purpose of this action of teachers is to force students to achieve "automatic response (As soon as students see the problem, they immediately know the solution and even the answer)" through frequent practice. Actually, appropriate exercises and review are conducive to strengthening memory and preventing forgetting process. However, the degree of practice is limited. The experiment found that after people have initially mastered learning contents, if they can practice the learning contents to make the learning degree reach $150 \%$, which will strengthen their memory ( $\mathrm{Lu} \& \mathrm{Wu}, 2014$, p. 179). That is to say, when the learning frequency is about $150 \%$, the students' learning effect is the best. Once, it exceeds 150\%, the students' learning effect will not increase. On the contrary, students will be mentally tired and drop concentration, resulting in poor learning. In China's current education, the most powerful performance of this phenomenon is the repeated review of the third grade of junior high school. In the first grade and the second grade of junior high school, teachers urge students to 
finish all learning contents that they should have been finished in junior high school during three years. In the third year of junior high school, teachers force students to review the same contents that have been learned in the first and second grades of junior high school over and over again.

\section{Students Are Forced to Learn Contents That Far Beyond Their Abilities}

For example, in order to make students stand out in the exams, some teachers improve the difficulty of teaching contents compulsively, completely ignoring the students' zone of proximal development. Vygotsky believed that the best teaching effect can only occur in the zone of proximal development, and those learning tasks that are slightly beyond the students' ability can effectively stimulate students' cognitive conflicts and promote their intellectual development (Wang, Yan, \& Zheng, 2016, p. 170). But difficult tasks that are beyond students' ability are difficult for them to achieve good results. In addition, in order to deepen students' understanding of knowledge, some teachers and parents deliberately raise the difficulty of the exercises in the weekday practice. A study shows that Chinese primary school mathematics questions are more difficult to understand in terms of cognitive requirements and background than Germany (Gong, He, Wang, Xu, \& Tao, 2014). The difficulty of Chinese junior high school mathematics questions is also in the upper ranks of many countries (Wu, Wang, \& Cao, 2014). The difficult exercises have spurred the students' enthusiasm for learning and increased the students' academic burden.

But it is important to point out that students' learning does have a process from feeling boring to discovering interesting, from unwilling to learning to being willing to learn. But some teachers and parents cannot force students to learn when students have resistance to learning. Instead, teachers and parents should create interesting situations to guide students to learn, so as to help them overcome the lazy feelings that they do not want to learn.

\section{Hazards of "Forced Learning"}

"Forced learning" is a wrong way of learning. On the surface, it is to fully explore the potential of students, but actually it has caused immeasurable consequences for the physical and mental health and long-term development of students.

\section{“Forcing Learning” Alienated the Meaning of Students' Learning and Destroyed the Nature of Students}

As we all know, people are born with desire and curiosity to explore, and students are no exception. Therefore, the initial learning behavior of students is spontaneous and active, based on their own needs and interests rather than being forced. This spontaneous learning behavior is derived from the nature of the students and is also the meaning of the students' learning. However, in the actual educational situation, some parents and teachers have neglected the inherent nature of students' learning that students are willing to learn and love learning. Some parents and teachers even deliberately narrow down and squeeze this nature. Driven by exam-oriented education and utilitarian education, some parents and teachers repeatedly urge students to learn in content, time, frequency, and difficulty, and filled students' mind with various standardized and mechanized knowledge to force students to remember and practice in order to "efficiently" pursue high academic scores. At this time, the "efficient effect" is not the benefit of children's creative development and life experience, but the efficiency of mechanical acceptance of knowledge (Zhou \& Xian, 2016). Students in the forced situation have no interest in learning and no novelty to explore the unknown world, not to mention they do not experience the joy of learning. Most students are just boring to learn objective knowledge and indirect experience. In this 
process, students just try to escape from the external pressure of parents and teachers. Some students can only be forced to follow the hard passwords of parents and teachers "must do this" to mechanically learn the prescriptive knowledge. Nature of students has no room to play under such circumstances, can only passively adapt this situation. Under such an atmosphere of forcing students to learn, all people, including the students themselves, cannot recognize the existence of nature, let alone protect nature (Yan \& Zhu, 2012). Repressing students' nature can only be exchanged for short-term academic record, but it has caused immeasurable harm to the future development of students. For example, some prodigies created by "forced learning” seem to be very excellent at the time, but ultimately they are also difficult to become talents. Because "forced learning" has already buried the negative emotions that they are tired of learning in the hearts of these students.

\section{“Forcing Learning” Reduced Students' Interest in Learning and Overdrew Students' Potential}

Under the background of increasingly fierce competition, "Cannot let the child lose on the starting line" is a classic reason for some parents and teachers to force students to learn knowledge prematurely and excessively. However, while learning time is prolonged, learning content is increased, and practice frequency is increased, students are very painful. On the one hand, students are forced to repress their interest in learning and they can't feel the joy of learning. Because most of parents and teachers are short-sighted. For most parents and teachers, learning is to get high marks. They often put good grades and first-class university in mind, but excluded learning pleasure from their considerations. These parents and teachers just cram students into mechanical training, and force them to remember a set of standard answers, conventional ideas, and solving methods, which undoubtedly greatly frustrates students’ interest in learning. John Dewey (1994, p. 170) said, "Self-initiated activities are the core component of interest behavior. Simple hard work can only create irresponsible, stubborn, narrow-minded people, because there is no spontaneous interest". In other words, when students lose interest in learning, they will not really engage in learning, so their future development is predictable: mechanical, clumsy, and irresponsible. There is no real learning without interest. When students lose interest in learning, it indicates that they will lack the goal and motivation of self-development for a long time or their whole life. On the other hand, “forced learning” hinders the development of students' creativity, and reduce their imagination and thinking space. Creation is the essential quality of modern and future talents. Creative activities need take time and creative thinking requires waiting for opportunities. Therefore, students who are forced to learn in a hurry or in accordance with the instructions are unlikely to be creative. At the same time, "forced learning" binds students to objective knowledge, so that these students often do not have skepticism and critical thinking. They tend to develop thinking styles and psychological habits, such as respect for authority, self-restraint, and good at memory, which hinder students' creativity development.

\section{“Forcing Learning” Distorted the Psychology of Students and Harmed Students' Physical and Mental Health}

Students have suffered too many parents' expectations and teachers' external pressure. Some parents and teachers force some students to study hard, making them tired of coping with parents and teachers' external coercion, so many students often feel depressed and bored, even nervous or scared. The most direct consequence of these psychological disorders is insomnia that students do not have enough time to sleep during the day and are unable to sleep at night because of anxiety. As time goes on, students will easily reduce academic performance or even become neurasthenia. In addition, “forced learning” restricts students' time to participate in games and sports, which greatly affects the healthy development of students' personality and psychology. Students are prone to form distorted psychology, such as loneliness, blockage, stubbornness, or 
sophistry. "Forced learning" is often accompanied by verbal or action disciplinary actions by parents and teachers. The students who are often beaten and scolded are usually cautious and conservative and obey their parents and teachers because they are afraid of being punished. Over time, these students tend to form unhealthy personality, such as inferiority, cowardice, and pessimism. When the compulsion exceeds the physiological and psychological acceptable limits of students, the possibility of suicide by some vulnerable students is increased. In addition, “forced learning” occupies a large amount of students' exercise time, resulting in students getting worse physical fitness due to lack of necessary physical exercise, such as lung capacity, exercise speed, and other physical indicators showed a significant downward trend. It not only affects the normal growth of students, but also causes other diseases of students, such as the rising rate of myopia and the increasing obesity. Healthy body and mind is the foundation of development. "Forced learning" at the expense of students' health can only get an external and short-term learning score, but it loses the foundation of students' long-term development. When students' physical health is consumed in advance, what do they take to enjoy the joy of success and the happiness of life? Such learning is not necessary, and it does more harm than good.

\section{Coping Strategies of "Forced Learning"}

In order to change the current situation of "forced learning", parents and teachers should establish correct educational concepts, adopt correct educational methods, and scientifically guide students in learning and psychology, so as to encourage students to grow healthily and learn happily.

\section{Parents and Teachers Should Clarify the Nature of Knowledge and Broaden the Way Students Acquire} Knowledge

An important reason for "forced learning" is the narrow understanding of knowledge by some parents and teachers. They mistakenly narrow knowledge into symbolic knowledge, and regard the mastery of symbolic knowledge as the dominant indicator of students' learning effect, so they are crazy about the symbolic result of "score", which in turn forces students to learn excessively. In view of this, it is necessary for parents and teachers to correct the misunderstanding of knowledge in time and establish a correct view of knowledge. Of course, parents and teachers should also have a clear grasp of the way to obtain knowledge. On the one hand, knowledge is a pluralistic and complex concept with rich connotations. But "forced learning" narrows the rich meaning of knowledge, and limits students' learning to the mastery of symbolic knowledge, ignoring the learning of other types of knowledge, such as operational knowledge and practical knowledge. According to Gardner's theory of multiple intelligences, we should develop students' diverse knowledge and abilities, and should not only focus on the learning of symbolic knowledge. Therefore, the first thing parents and teachers must do is to correctly understand the nature and connotation of knowledge and restore the original face of students' knowledge learning. On the other hand, parents and teachers should broaden the way students acquire knowledge. Students can not only acquire knowledge by accepting the knowledge of teachers. Students can experience knowledge, discover knowledge, and explore knowledge to obtain it. Constructivists believe that students can truly understand knowledge only by constructing knowledge on their own initiative. "Forced learning" only binds students to the passive acceptance of static knowledge and indirect experience, obliterating the subjective initiative of students in the process of obtaining knowledge and ignoring the students' meaningful construction of knowledge. Therefore, parents and teachers should learn to give up forcing students to learn in the process of guiding students, give full play to the subjectivity of students' learning, guide them to 
explore problems on their own, and help them to gain direct experience in inquiry and experience to deepen their understanding of knowledge.

\section{Parents and Teachers Should Activate Students' Inner Study Motive and Guide Them to Learn Consciously and Actively}

Learning itself is very enjoyable, and learning can only happen if there is no over-stress. Learning under excessive stress is only cultivating memory (Krishnamurti, 2010, p. 215). Nowadays, many students bear the triple "coercion" from parents, teachers, and society. Under such great pressure, some students cannot actually learn happily and efficiently. Coercion and punishment only make students passively fall into the embarrassing situation of "study painfully". In fact, we have always advocated students to study hard, but "hard study" is not the same as "painful learning". "Hard study" is a heartfelt activity from the students. "Hard study" is to pursue the meaning of learning and the joy of wisdom. Therefore, "hard study" is the embodiment of the correct learning concept. "Painful learning" is the negative impact of "forced learning", which violates students' willingness to learn and brings depression and torture to students' mind and body. It can be seen that parents and teachers cannot use the name of "supervising and guiding" to force students to learn. Instead, they should respect students' willingness to learn and start from the students' interests and hobbies to arouse the students' curiosity, and then stimulate their true Learning. As we all know, education does not shape students into what we expect, but helps and guides students to maximize their interests and strengths. Once, students have the interest and inner motivation to learn, they will willing to learn, and there will be no "forced learning". Therefore, parents and teachers should communicate with students more, listen to their opinions and ideas, and rationally develop their potential on the basis of fully understanding students' interest in learning. Secondly, parents and teachers should fully explore effective learning methods to help students choose better learning methods and guide them to learn consciously and actively. Correct and efficient learning methods, such as "interest learning” and "reflective learning” can not only give full play to students' initiative, but also help them develop good habits of learning independently. In short, parents and teachers should break through their rigid view of learning, correctly understand the meaning of students' learning, and guide students to learn actively and consciously.

\section{Parents and Teachers Should Create a Harmonious Educational Environment and Make Full Use of Students' “Children” Nature}

Rousseau (2001, p. 88) said, "Nature hopes that children will be like children before adulthood”. If we disrupt this order, it will cause some fruits to be precocious, they are neither full nor sweet, and will soon rot. In nature, precocious fruits are not the sweetest. Similarly, "premature children” created by "forced learning” will may not be the best. Children are children, they are not adults. We cannot look at children from the perspective of adults, and we cannot impose adult opinions and ideas on children. Therefore, parents and teachers cannot force students to learn contents that do not conform to the children's physical and mental development rules, and cannot increase the difficulty and frequency of their learning in an uncontrolled manner. Instead, parents and teachers should respect the relative independence of children development, lift the restrictions imposed on children, and encourage children to develop freely. In addition, parents and teachers should respect the particularities of children's learning styles and lifestyles. Children are born players and explorers. Games can provide children with a rich experience, and have an irreplaceable role in children's emotional and creative development. From birth, children experience the world directly with their bodies and senses. They want to touch everything and want to get something done, which can make them get the much needed learning 
(Rousseau, 2001, p. 48). Maslow's needs theory also clearly states that students can only pursue self-realization if they are psychologically safe. "Forced learning” not only suppresses students' “children nature”, but also brings a sense of tension and oppression to students, which is not good for students to learn happily. Based on this, parents and teachers should create a free and safe educational environment, guide students to engage in educational games and inquiry activities in a harmonious atmosphere and stimulate students' potential in experience and inquiry, thus triggering students' creative behavior instead of forcing the child to sit on the seat and concentrate on the symbolic learning.

\section{Parents and Teachers Should Strengthen Cooperation to Give Students Scientific Guidance on Psychology, Emotion, and Learning}

Parents and teachers should communicate in time, strengthen cooperation, and scientifically guide the students' learning, emotional, and psychological development in order to reduce or even eliminate compulsion. First of all, parents and teachers should communicate with each other in time to fully understand students' learning situation at school and at home in order to reduce the extra academic burden caused by duplication of work. At the same time, parents and teachers should moderately reduce the difficulty and frequency of students' learning, so that students can fully develop their interests. Besides, parents and teachers should help students plan their study, entertainment, sports, and rest time scientifically. This plan should pay attention to striking a proper balance between work and rest. Parents and teachers should also cultivate and improve students' time management ability, teach them scientific and efficient time management strategies, and guide them to make learning plans according to their actual needs, so as to reasonably allocate learning time. If students have enhanced the awareness of time management and formed the habit of saving time, they will cherish time and devote themselves to learning consciously. In this way, even if parents and teachers do not force students to study, students can take the initiative to learn. Secondly, parents and teachers should work together to scientifically guide students' emotions and psychology. In the context of a highly competitive society, students are under tremendous psychological pressure. However, due to the younger age, students' ability to manage their emotions and their mental management is weak, which requires the help and guidance of parents and teachers. Parents and teachers should pay full attention to the emotional and psychological changes of students, promptly guide students' negative emotional and psychological problems, and teach students the methods to vent their negative emotions and minds. Also, parents and teachers should "prepare for the rain" to prevent students' bad emotions and problems. This requires parents and teachers to fully appreciate and respect students, give them more encouragement and care, and less coercion and suppression to help students construct positive emotional attitudes.

\section{Conclusions}

"Forced learning" is a wrong way that parents and teachers repeatedly force students to learn in contents, time, frequency, and difficulty, so it caused bad consequences that some students' study took too much time, covered excess contents, is repeated too much and is too difficult. Undoubtedly, "forced learning” alienated the meaning of students' learning, destroyed the nature of students, reduced students' interest in learning, overdrew students' potential, distorted the psychology of students, and harmed students' physical and mental health. Therefore, parents and teachers are important others in the process of students' growth, they should assume the responsibility of guiding students to learn correctly, rather than forcing them. Cultivating students' interest in learning, adopting various learning methods to guide students to study, creating a harmonious educational 
environment, and making full use of students' "children" nature are all good ways to deal with "forced learning”. Parents and teachers should establish right educational ideas and strengthen cooperation to give students scientific guidance, so that students can learn happily and grow healthily.

\section{References}

Dewey, J. (1994). School and society: Tomorrow's school (X. L. Zhao, Z. Y. Ren, \& Z. H. Wu, Trans.). Beijing: People’s Education Press.

Gong, Z. K., He, S. Q., Wang, Y., Xu, H. Z., \& Tao, Z. Z. (2014). Comparative study on China elementary mathematics textbooks' difficulty with Germany: Taking China PEP mathematics textbooks and Germany Das Zahlenbuch textbook as examples. Primary \& Secondary Schooling Abroad, 12(11), 48-56.

Krishnamurti, J. (2010). The whole movement of life is learning (C. C. Zhang, Trans.). Beijing: Jiuzhou Press.

Lu, J. M., \& Wu, X. C. (Eds.). (2014). Modern psychology: Basic theory and educational applications. Shanghai: Shanghai People's Publishing House.

Rousseau, J. J. (2001). Emile-On education (P. O. Li, Trans.). Beijing: People’s Education Press.

Song, N. Q., \& Yang, X. (2014). A quantitative analysis of the heavy course load of Chinese primary and secondary school students. Educational Research, 35(3), 25-30.

Wang, F. Y., Yan, L. S., \& Zheng, H. (Eds). (2016). Educational psychology: A new look. Guangzhou: Jinan University Publishing House.

Wu, L. B., Wang, J. B., \& Cao, Y. M. (2014). The international comparative study of exercises in mathematics textbooks for junior high schools. Curriculum, Teaching Material and Method, 34(2), 112-117.

Yan, S. X., \& Zhu, N. B. (2012). Characterization, attribution and redemption of over education. Journal of the Chinese Society of Education, 12(8), 18-21.

Zhou, H. T., \& Xian, J. F. (2016). Criticism of disembodiment teaching culture and surpassing it-From the perspective of embodied cognition theory. Theory and Practice of Education, 36(22), 61-64. 